\title{
JORNAL DE Políticas Educacionals

\section{A razão pedagógica das atividades da diretora de Cmei do município de Curitiba e a sua relação com a qualidade do atendimento na educação infantil}

\section{The pedagogical reason of the activities of the Cmei director of the municipality of curitiba and its relationship with the quality of care in child education}

\section{La razón pedagógica de las actividades de la directora de Cmei del municipio de Curitiba y su relación con la calidad de la atención en la educación infantil}

Danieli D'Aguiar Cruzetta ${ }^{1}$

Citação: CRUZETTA, D. D. A razão pedagógica das atividades da diretora de Cmei do município de Curitiba e a sua relação com a qualidade do atendimento na educação infantil. Jornal de Políticas Educacionais. V. 12, n. 22. Novembro de 2018.

\begin{abstract}
Resumo
A presente pesquisa teve como objetivo analisar de que forma as atividades desenvolvidas no cotidiano de trabalho das diretoras dos Centros Municipais de Educação Infantil de Curitiba (Cmeis) influenciam na qualidade do atendimento oferecido às crianças, no sentido de refletir acerca da razão pedagógica do seu trabalho. A metodologia consistiu na aplicação de questionários às diretoras dos Cmeis no ano de 2016, buscando informações do seu cotidiano de trabalho e da gestão da instituição, além da análise de documentos locais e nacionais acerca da qualidade da educação infantil. Com base em oito critérios de condições de oferta, elaborados pela pesquisadora, foi analisado de que forma a frequência de atividades da diretora relaciona-se com elas. A pesquisa mostrou que, para além das atividades com características mais pedagógicas, outras podem ter relação mais direta ou indireta com a qualidade da Educação Infantil, evidenciando que as atividades administrativas também podem ter sua razão pedagógica para existir.

Palavras-chave: Qualidade da educação; Gestão Escolar; Papel do diretor; Educação Infantil; Políticas Educacionais.
\end{abstract}

\footnotetext{
${ }^{1}$ Mestra em Educação (UFPR). Professora da Rede Municipal de Ensino de Curitiba - PR. E-mail: cruzettadanieli@gmail.com.
} 


\begin{abstract}
The present research had as objective to analyze how the activities developed in the daily work of the directors of the Municipal Centers of Early Childhood Education in Curitiba (CMEIs) influence the quality of care offered to children, in order to reflect on the pedagogical reason of their work. The methodology consisted in the application of questionnaires to the directors of the CMEIs in 2016, seeking information on their daily work and the management of the institution, as well as the analysis of local and national documents on the quality of early childhood education. Based on eight criteria of offer conditions, elaborated by the researcher, it was analyzed how the frequency of the director activities relates to themselves. The research showed, in addition to activities with more pedagogical characteristics, others may have a more direct or indirect relationship with the quality of Early Childhood Education, evidencing that administrative activities may also have their pedagogical reason to exist.

Palavras-chave: Quality of education; School administration; Role of the director; Child education; Educational Policies.
\end{abstract}

\title{
Resumen:
}

La presente investigación tuvo como objetivo analizar de qué forma las actividades desarrolladas en el cotidiano de trabajo de las directoras de los Centros Municipales de Educación Infantil de Curitiba (CMEI) influencian en la calidad de la atención ofrecida a los niños, en el sentido de reflexionar acerca de la razón pedagógica de su trabajo. La metodología consistió en la aplicación de cuestionarios a las directivas de los CMEI en el año 2016, buscando informaciones de su cotidiano de trabajo y de la gestión de la institución, además del análisis de documentos locales y nacionales acerca de la calidad de la educación infantil. Con base en ocho criterios de condiciones de oferta, elaborados por la investigadora, se analizó de qué forma la frecuencia de actividades de la directora se relaciona con ellas. La investigación mostró que, además de las actividades con características más pedagógicas, otras pueden tener relación más directa o indirecta con la calidad de la Educación Infantil, evidenciando que las actividades administrativas también pueden tener su razón pedagógica para existir.

Palabras clave: Calidad de la educación; Gestión Escolar; Papel del diretor; Educación Infantil; Políticas Educativas.

\section{Introdução}

0 presente trabalho teve como objetivo analisar as tarefas cotidianas da diretora $^{2}$ de Cmei (Centro Municipal de Educação Infantil) do município de Curitiba-PR, buscando a razão pedagógica que justifica a existência das atividades que são desenvolvidas em seu cotidiano de trabalho e relacionando com a qualidade do atendimento que é oferecido para as crianças que frequentam a educação infantil (EI).

Nesse extrato de uma pesquisa mais ampla (CRUZETTA, 2018), buscou-se argumentar acerca da superação da divisão entre atividades administrativas e pedagógicas realizadas pela diretora, fazendo uso dos seguintes caminhos metodológicos: a) questionários aplicados às diretoras e; b) análise documental. 0 questionário teve como objetivo conhecer o perfil das diretoras e saber como organizam seu cotidiano de trabalho. Para tanto, ele foi organizado em três seções de perguntas. A primeira refere-se ao cotidiano do trabalho na direção, a segunda sobre o perfil das diretoras e a terceira sobre a gestão do Cmei, sendo enviado para as 205 unidades em

\footnotetext{
${ }^{2}$ Como mais de $97 \%$ das diretoras de Cmei no município de Curitiba são mulheres, fará uso do gênero
} feminino ao tratar dessas profissionais. 
funcionamento no ano de 2016. Foram obtidas 175 respostas, o que corresponde a 85,3\% do total de diretoras. Para esta pesquisa, delimitou-se à análise da primeira e terceira seção. A análise documental fez uso dos documentos nacionais que norteiam e normatizam a Educação Infantil no Brasil e documentos que norteiam essa etapa da Educação Básica na Rede Municipal de Ensino de Curitiba-PR.

Para se chegar a um critério que estabelecesse a razão pedagógica das atividades desenvolvidas pelas diretoras, a pesquisa apoiou-se em estudos sobre os documentos nacionais e regionais que orientam a EI e na análise das pesquisas que tratam sobre a qualidade do atendimento dessa etapa de ensino, estabelecendo oito condições de qualidade que tratam da organização dos ambientes, dos eixos de trabalho, interação e brincadeiras, práticas educativas que trabalham as diferentes linguagens e garantam experiências de aprendizagem, desenvolvimento da identidade, qualificação dos profissionais e gestão democrática. Na sequência as atividades que estavam elencadas na seção I do questionário foram relacionadas às atribuições legais estabelecidas em Regimento de Cmei e, por fim, foram relacionadas às atividades desenvolvidas no cotidiano de trabalho das diretoras com as condições de qualidade do trabalho, percebendo assim a razão pedagógica que justifica a sua existência, independente de suas características iniciais serem mais administrativas ou pedagógicas.

Os resultados mostraram que o trabalho da diretora de Cmei influencia a qualidade da Educação Infantil. Assim, observou-se a superação da divisão entre atividades administrativas e atividades pedagógicas, pois a pesquisa mostrou que as tarefas podem ter relação direta ou indireta com a qualidade da Educação Infantil, evidenciando que as atividades administrativas também podem ter sua razão pedagógica para existir, mesmo que indiretamente. Inicia-se o trabalho a partir de uma discussão sobre a qualidade da EI.

\section{Qualidade da Educação Infantil}

Para discutir o conceito de qualidade da educação é necessário levar em consideração os aspectos de diversidade, de valores e contexto de cada lugar, pois entende-se que qualidade é um conceito relativo, baseado em valores e crenças (MOSS, 2011). É um conceito que envolve concepções de mundo, de sociedade e de educação, ou seja, socialmente construído. 
A questão da qualidade pode também ser discutida pela perspectiva de qualidade social, que, para efeitos de melhoria da educação, considera os contextos social, cultural e econômico de cada lugar, assim como fatores internos e externos à escola, visando assim à diminuição das desigualdades sociais e educacionais (DOURADO; OLIVEIRA, 2009; SILVA, 2009).

Algumas pesquisas que se referem à qualidade do atendimento nas instituições de EI mostram índices insatisfatórios e sugerem critérios que podem ser utilizados para avaliação da qualidade (CAMPOS; FÜLLGRAF; WIGGERS, 2006; CARVALHO; PEREIRA, 2008; CAMPOS; ESPOSITO; BHERING; GIMENES; ABUCHAIM, 2011; CAMPOS, 2013; MELHUISH, 2013; BRASIL, 2015). Fica evidente, nesse quadro, que uma possível avaliação se concentra às condições de qualidade relacionadas à infraestrutura, material, pessoal e organização do trabalho.

Essas pesquisas apontam também para as diferenças regionais, sociais, de acesso e permanência, de oportunidades educacionais, o que reforça a ideia de que o conceito de qualidade é socialmente construído por indivíduos que participam daquela realidade, caracterizando-se como resultado de um processo participativo e democrático.

Nesse sentido, diferentes autores, pesquisas e documentos nacionais e regionais apontam que a discussão sobre qualidade da educação deve ser realizada por meio de parâmetros que consideram as dimensões política, pedagógica e administrativa.

Em busca de parâmetros que pudessem apontar condições iniciais para a qualidade do atendimento de uma instituição que oferta a Educação Infantil, utilizou-se para o caso de Curitiba-PR os Parâmetros Indicadores de Qualidade - PIQ -, um documento local construído para que os Cmeis tivessem um instrumento de autoavaliação, e as Diretrizes Curriculares Nacionais para a Educação Infantil - Dcnei. Com isso, foram estabelecidos pela autora oito critérios de condições de qualidade para as referidas instituições:

- Que os espaços das unidades sejam organizados com o intuito de garantir um tempo de infância a ser vivido, levando em consideração critérios de segurança, saúde, conforto e estética, flexibilidade, interação e acessibilidade;

- Que a brincadeira seja considerada como principal linguagem da criança e que, para tanto, ela tenha acesso a brinquedos seguros e estimulantes em 
diferentes tempos e espaços, brinquedos e brincadeiras variadas que favoreçam diferentes vivências afetivas, sociais, cognitivas e motoras e um ambiente que favoreça as brincadeiras de faz de conta. Tendo como critério para essa organização e aquisição de materiais segurança, saúde, quantidade, qualidade, diversidade e acessibilidade;

- Que os tempos e espaços de alimentação estejam organizados com o intuito de garantir que as crianças desenvolvam ações independentes para se alimentar e que desenvolvam o gosto e prazer por uma alimentação saudável. Que incentivem ainda a amamentação dos bebês com o aleitamento materno. Deve-se levar em consideração os critérios de segurança, conforto e estética, saúde e acessibilidade;

- Que as crianças tenham oportunidade de desenvolver identidades singulares e autônomas por meio do critério de acessibilidade;

- Que as crianças vivenciem interações que proporcionem um ambiente favorável ao respeito, à proteção, às relações de afeto, à solidariedade e amizade, tendo como critério para a organização a integração e o respeito;

- Que as crianças tenham acesso a experiências que proporcionem o desenvolvimento da curiosidade, imaginação e capacidade de expressão tendo possibilidade de desenvolver conhecimento de si e do mundo; ter interação com as diversas linguagens, gestual, verbal, plástica, dramática e musical; ter interação com a linguagem oral e escrita, tendo acesso a diferentes suportes e gêneros textuais orais e escritos; ações que recriem relações quantitativas, medidas, formas e orientações espaço temporais; propostas que desenvolvam a autonomia nas ações de cuidado pessoal, auto-organização, saúde e bem-estar; acesso a diferentes manifestações de música, artes plásticas e gráficas, cinema, fotografia, dança, teatro, poesia e literatura; contato e cuidado com a natureza; construção de conhecimentos em relação ao mundo físico e social, ao tempo e à natureza; acesso às diferentes manifestações e tradições culturais brasileiras; e utilização de recursos tecnológicos e midiáticos. Tendo como critério saúde e segurança, uso de materiais e equipamentos, quantidade, qualidade, diversidade e acessibilidade; 
- Que todos os professores que trabalham na Educação Básica, inclusive os da Educação Infantil, em consonância com a meta 15 do atual Plano Nacional de Educação, tenham formação específica em ensino superior, complementada com a formação continuada em serviço, usando como critério para organização a acessibilidade;

- Que os Cmeis estejam organizados a fim de garantir um espaço de convivência democrática, usando como critério de organização a transparência, o planejamento participativo, atenção à equipe, parceria e avaliação da instituição.

Pensando na qualidade como construída socialmente por meio de processos de autoavaliação e de avaliação institucional, o que envolve as dimensões política, pedagógica e administrativa, considera-se a participação da diretora em todos os aspectos levantados e não apenas especificamente nas condições que tratam exclusivamente da gestão da unidade. Considerando a diretora como uma pessoa na centralidade dos processos decisórios do Cmei, a coordenadora do processo educativo, e, por consequência, de provável influência nas condições para que o trabalho aconteça, sendo a coordenadora do processo educativo, a seção seguinte visa a discutir as dimensões da função desse sujeito.

\section{Dimensões da Função da Diretora Escolar}

Concorda-se com Souza (2007) ao compreender a função da diretora escolar como uma função político-pedagógica que contempla três dimensões: a face política, a face pedagógica e a face administrativa. Ou seja, nessa perspectiva, a diretora de escola age politicamente nas faces pedagógica e administrativa de sua função. Nesse sentido, o autor discute a centralidade pedagógica que deve existir nos processos de gestão escolar, pois essa é uma dimensão de importante influência na busca do objetivo educacional, que, no limite, é fazer com que os estudantes aprendam mais e melhor, pois a razão de ser da escola é pedagógica e a gestão deve estar voltada para esse fim. Portanto entende-se que as atividades desenvolvidas pela diretora escolar devem estar justificadas por sua razão pedagógica. 0 autor destaca que essas faces não são hierarquizadas e sim complementares, e, para exercer a função de diretora, é preciso conhecimento tanto da face administrativa como da face pedagógica da função. 
Entende-se que a face administrativa e a face pedagógica são distintas da mesma função e o conhecimento desses dois campos é essencial para o sujeito que ocupa o lugar de diretora de escola. Porém a atuação política nessas faces implica na necessidade de dominação dos aspectos políticos de sua função, pois "a função do diretor é a de coordenar o trabalho geral da escola, lidando com os conflitos e com as relações de poder, com vistas ao desenvolvimento mais qualificado do trabalho pedagógico" (SOUZA, 2007, p. 153).

Sendo assim, é preciso considerar a superação entre a divisão das tarefas administrativas e tarefas pedagógicas, pois, ao existir uma razão pedagógica para que ela seja realizada pela diretora e esteja em consonância com a finalidade educativa da unidade, ela não pode ser considerada só como administrativa, pois, conforme salientado anteriormente, a razão de existir da escola é pedagógica e a gestão deve estar organizada para atingir a esse fim (SOUZA, 2007).

É preciso entender que o pedagógico não se faz no vazio, ele é um conjunto de ações, e a diretora é a responsável pela coordenação e convergência dessas atividades. Para tanto, a diretora escolar, como coordenadora do processo de gestão escolar, deve considerar e privilegiar em seu cotidiano ações que tenham a razão pedagógica de ser, buscando assim atingir os objetivos da escola. As atividades administrativas e as atividades pedagógicas devem ser complementares e não excludentes. Para a Educação Infantil, podemos colocar que o parâmetro é o direito da criança, refletir se a ação da diretora alarga ou restringe o direito da criança de frequentar uma Educação Infantil de qualidade.

Assim, a razão pedagógica da atividade é definida quando uma tarefa está voltada para atingir o objetivo fim da instituição escolar. No caso da pesquisa, limita-se a entender se ela está voltada para favorecer as condições de qualidade para educação infantil estabelecidas neste trabalho.

Ao discutir a qualidade da Educação Infantil e o papel da diretora de Cmei, a teoria indicou que o trabalho da diretora influencia na qualidade, pois a dimensão da gestão escolar é considerada como um dos critérios a ser debatido na questão da qualidade e a diretora como principal sujeito da gestão escolar, pelo perfil de suas atribuições na face política, pedagógica e administrativa. Tais reflexões foram fundamentais para a análise durante a pesquisa empírica. 
Existem atribuições que a diretora de Cmei no município de Curitiba tem oficialmente postas no regimento da unidade. No quadro 1 foi realizada uma relação dessas atribuições com as atividades que são realizadas no cotidiano de trabalho das diretoras. As atividades que a diretora desenvolve em seu cotidiano que foram elencadas no questionário enviado a esses sujeitos foram categorizadas de acordo com as atribuições para que se possa visualizar de que forma cada atribuição está sendo desempenhada pelas diretoras de Cmei.

QUADRO 1 - ATRIBUIÇÕES OFICIAIS DA DIRETORA E SEU COTIDIANO DE TRABALHO

\begin{tabular}{|c|c|}
\hline $\begin{array}{c}\text { ATRIBUIÇÕES DA DIRETORA ELENCADAS NO } \\
\text { REGIMENTO DO Cmei }\end{array}$ & $\begin{array}{c}\text { COTIDIANO DO TRABALHO ELENCADAS NO } \\
\text { QUESTIONÁRIO } \\
\end{array}$ \\
\hline $\begin{array}{l}\text { I - definir, em conjunto com o Conselho do Cmei, a } \\
\text { Proposta Pedagógica e o Regimento da instituição, } \\
\text { em consonância com as diretrizes da Secretaria } \\
\text { Municipal da Educação e legislação vigente; }\end{array}$ & Participar das reuniões de conselho \\
\hline \multirow{3}{*}{$\begin{array}{l}\text { II - administrar o Cmei consoante à legislação } \\
\text { vigente, de forma a assegurar a execução da } \\
\text { Proposta Pedagógica; }\end{array}$} & Elaborar e avaliar o plano de ação \\
\hline & $\begin{array}{l}\text { Participar de formações nos Núcleos Regionais } \\
\text { de Educação }\end{array}$ \\
\hline & $\begin{array}{l}\text { Participar de formações ofertadas pelo } \\
\text { Departamento de Educação Infantil }\end{array}$ \\
\hline \multirow{3}{*}{$\begin{array}{l}\text { III - definir alternativas de soluções com o suporte } \\
\text { técnico-pedagógico e a equipe da unidade, para as } \\
\text { dificuldades que se apresentarem; }\end{array}$} & $\begin{array}{l}\text { Organizar as faltas de professores e as } \\
\text { permanências }\end{array}$ \\
\hline & Realizar reuniões com os professores (as) \\
\hline & Solucionar conflitos entre funcionários \\
\hline $\begin{array}{l}\text { lV - organizar, em conjunto com o suporte técnico- } \\
\text { pedagógico, a distribuição das funções, } \\
\text { considerando a legislação vigente e os critérios } \\
\text { estabelecidos pela Secretaria Municipal da } \\
\text { Educação; }\end{array}$ & $\begin{array}{l}\text { Participar de reuniões com o pedagogo (a) para } \\
\text { tratar de assuntos pedagógicos }\end{array}$ \\
\hline \multirow{3}{*}{$\begin{array}{l}\text { V - supervisionar os trabalhos desenvolvidos pelos } \\
\text { profissionais da educação, objetivando a garantia } \\
\text { das propostas pedagógicas para as diferentes faixas } \\
\text { etárias atendidas na unidade; }\end{array}$} & $\begin{array}{l}\text { Participar de reuniões com o pedagogo (a) para } \\
\text { tratar de assuntos pedagógicos }\end{array}$ \\
\hline & $\begin{array}{l}\text { Participar dos momentos de permanência com } \\
\text { os profissionais }\end{array}$ \\
\hline & Observar propostas em sala \\
\hline \multirow[t]{2}{*}{$\begin{array}{l}\mathrm{Vl} \text { - participar do planejamento do trabalho } \\
\text { educacional realizado com as crianças; }\end{array}$} & $\begin{array}{l}\text { Participar dos momentos de permanência com } \\
\text { os profissionais }\end{array}$ \\
\hline & Observar as propostas em sala \\
\hline \multirow{7}{*}{$\begin{array}{l}\text { Vll - promover canais de comunicação de forma a } \\
\text { garantir o fluxo de informações fidedignas entre o } \\
\text { Cmei e os setores da Secretaria Municipal da } \\
\text { Educação, visando à qualidade do processo } \\
\text { pedagógico-administrativo; }\end{array}$} & $\begin{array}{l}\text { Participar dos momentos de supervisão com o } \\
\text { Núcleo Regional de Educação }\end{array}$ \\
\hline & Participar de reuniões com a CANE regional \\
\hline & Atender a demandas do NRE e do nível central \\
\hline & Realizar repasses às equipes \\
\hline & Participar de reunião com a chefia de núcleo \\
\hline & $\begin{array}{l}\text { Participar de reunião com o Departamento de } \\
\text { Educação Infantil }\end{array}$ \\
\hline & $\begin{array}{l}\text { Participar de reuniões com outros setores da } \\
\text { Secretaria Municipal de Educação }\end{array}$ \\
\hline $\begin{array}{l}\text { VIII - ass } \\
\text { aprovado, }\end{array}$ & $\begin{array}{l}\begin{array}{l}\text { Organizar as faltas de professores e as } \\
\text { permanências }\end{array} \\
\end{array}$ \\
\hline
\end{tabular}


CRUZETTAA, D. D. A razão pedagógica das atividades da diretora de Cmei do município de Curitiba e a sua relação com a qualidade do atendimento na educação infantil

\begin{tabular}{|c|c|}
\hline previstos; & Substituir professores (as) em sala \\
\hline \multirow{2}{*}{$\begin{array}{l}\text { IX - promover ações conjuntas com a família, } \\
\text { comunidade e outros órgãos, articulando-as às } \\
\text { propostas pedagógicas do Cmei; }\end{array}$} & Atender as famílias \\
\hline & Realizar reuniões com as famílias \\
\hline \multirow{3}{*}{$\begin{array}{l}\mathrm{X} \text { - efetuar o controle de pessoal, bem como a } \\
\text { supervisão dos serviços de manutenção, vigilância e } \\
\text { serviços gerais; }\end{array}$} & Atender situações de manutenção \\
\hline & Avaliar os serviços terceirizados \\
\hline & $\begin{array}{l}\text { Realizar reuniões com os profissionais dos } \\
\text { serviços terceirizados }\end{array}$ \\
\hline \multirow{4}{*}{$\begin{array}{l}\mathrm{Xl} \text { - monitorar todos os processos relativos à } \\
\text { documentação da instituição e das crianças, } \\
\text { orientando sobre os procedimentos de registros, } \\
\text { prazos e arquivos; }\end{array}$} & Realizar BF mensal \\
\hline & Cadastrar LTS de subordinados \\
\hline & Inserir dados das crianças no GED \\
\hline & $\begin{array}{l}\text { Acompanhar o trabalho do agente } \\
\text { administrativo }\end{array}$ \\
\hline \multirow{3}{*}{$\begin{array}{l}\text { Xll - supervisionar o fornecimento e qualidade da } \\
\text { alimentação para as crianças; }\end{array}$} & Avaliar os serviços terceirizados \\
\hline & Conferir a alimentação \\
\hline & $\begin{array}{l}\text { Acompanhar os momentos de alimentação das } \\
\text { crianças }\end{array}$ \\
\hline $\begin{array}{l}\text { Xlll - coordenar o processo de matrículas das } \\
\text { crianças, de acordo com as diretrizes da Secretaria } \\
\text { Municipal da Educação e com a participação do } \\
\text { Conselho do Cmei; }\end{array}$ & Realizar matrícula \\
\hline $\begin{array}{l}\text { XIV - manter o cadastro das crianças lotadas na } \\
\text { unidade; }\end{array}$ & Realizar cadastros de matrícula \\
\hline \multicolumn{2}{|l|}{$\begin{array}{l}X V-\quad \text { Responsabilizar-se pelos materiais } \\
\text { permanentes e equipamentos, orientando quanto ao } \\
\text { seu uso e à sua conservação; }\end{array}$} \\
\hline \multirow{3}{*}{ 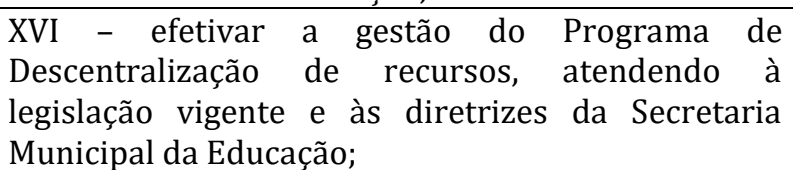 } & Realizar orçamentos para compras \\
\hline & Realizar compras \\
\hline & Realizar prestação de contas \\
\hline $\begin{array}{l}\text { XVII - presidir o Conselho do Cmei - órgão máximo } \\
\text { de direção da instituição - garantido a participação } \\
\text { de todos os segmentos da comunidade do Cmei, } \\
\text { respondendo pelas decisões consensadas no } \\
\text { colegiado; }\end{array}$ & Participar das reuniões de conselho \\
\hline \multirow{2}{*}{$\begin{array}{l}\text { XVII - presidir o Conselho do Cmei - órgão máximo } \\
\text { de direção da instituição - garantido a participação } \\
\text { de todos os segmentos da comunidade do Cmei, } \\
\text { respondendo pelas decisões consensadas no } \\
\text { colegiado; }\end{array}$} & Participar das reuniões de conselho \\
\hline & Elaborar e avaliar o plano de ação \\
\hline $\begin{array}{l}\text { XVIII - efetivar parcerias aprovadas pelo Conselho } \\
\text { do Cmei, atendendo à legislação vigente e diretrizes } \\
\text { da Secretaria Municipal da Educação; }\end{array}$ & Participar de reuniões com a Rede de Proteção \\
\hline \multirow[t]{5}{*}{ XIX - realizar outras atividades pertinentes. } & Acompanhar a entrada e/ou saída das crianças \\
\hline & $\begin{array}{l}\text { Realizar encaminhamentos para a unidade de } \\
\text { saúde }\end{array}$ \\
\hline & $\begin{array}{l}\text { Realizar reuniões com profissionais } \\
\text { especializados que atendem as crianças }\end{array}$ \\
\hline & Responder e-mails \\
\hline & Organizar malote \\
\hline
\end{tabular}

Fonte: Cruzetta (2018).

Na sistematização das informações, algumas tarefas aparecem em mais de uma atribuição da função da diretora do Cmei. Outras atribuições têm um número maior de 
atividades que estão relacionadas a elas. Ainda há uma atribuição que não apresentou relação com nenhuma das atividades da lista do questionário. Porém percebe-se como as atividades realizadas pela diretora em seu cotidiano de trabalho estão relacionadas com as atribuições oficiais desse sujeito. Portanto na seção a seguir será discutida a razão pedagógica que justifica a existência dessas atividades.

\section{A razão pedagógica das atividades desenvolvidas pela diretora de Cmei}

$\mathrm{Na}$ discussão feita anteriormente a respeito das tarefas administrativas e pedagógicas que são desenvolvidas pela diretora, percebeu-se que algumas apresentam características iniciais que são mais administrativas ou mais pedagógicas, sendo a maioria delas aproximada com a primeira.

Porém o que se pretende mostrar com essa discussão é que as atividades que apresentam características iniciais que são mais administrativas apresentam uma razão pedagógica para existir, como as tarefas relacionadas à parte financeira, a tarefa de acompanhar as situações de manutenção, de organizar as faltas de professores e a horaatividade, entre outras. À primeira vista, essas são tarefas apenas administrativas, mas, ao pensar que sem elas o Cmei pode funcionar com menor qualidade, entende-se a razão pedagógica de elas existirem.

Nesse sentido, com o intuito de analisar qual a razão pedagógica de cada uma das atividades que a diretora desenvolve no seu dia a dia (atividades essas elencadas no questionário enviado às diretoras dos Cmeis de Curitiba), foi construído um quadro com as condições de qualidade para a Educação Infantil dos Cmeis, categorizando as atividades e a frequência das atividades desenvolvidas pela diretora que favorecem as condições de qualidade.

QUADRO 2 - ATIVIDADES DA DIRETORA QUE FAVORECEM QUE AS CONDIÇõES DE QUALIDADE DA EI DOS CMEIS DE CURITIBA SEJAM ALCANÇADAS

\begin{tabular}{|c|c|c|c|}
\hline \multirow[t]{2}{*}{ CONDIÇÃO DE QUALIDADE } & \multirow[t]{2}{*}{$\begin{array}{l}\text { ATIVIDADE DESENVOLVIDA } \\
\text { PELA DIRETORA }\end{array}$} & \multicolumn{2}{|c|}{$\begin{array}{c}\text { FREQUÊNCIA } \\
\%\end{array}$} \\
\hline & & MENOR & MAIOR \\
\hline \multirow{3}{*}{$\begin{array}{l}\text { Que os espaços das unidades sejam } \\
\text { organizados com o intuito de garantir } \\
\text { um tempo de infância a ser vivido, } \\
\text { levando em consideração critérios de } \\
\text { segurança, saúde, conforto e estética, } \\
\text { flexibilidade, interação e acessibilidade. }\end{array}$} & Observar as propostas em sala & 21,14 & 78,86 \\
\hline & Atender situações de manutenção & 2,86 & 97,14 \\
\hline & Avaliar os serviços terceirizados & 8,00 & 92,00 \\
\hline
\end{tabular}


CRUZETTAA, D. D. A razão pedagógica das atividades da diretora de Cmei do município de Curitiba e a sua relação com a qualidade do atendimento na educação infantil

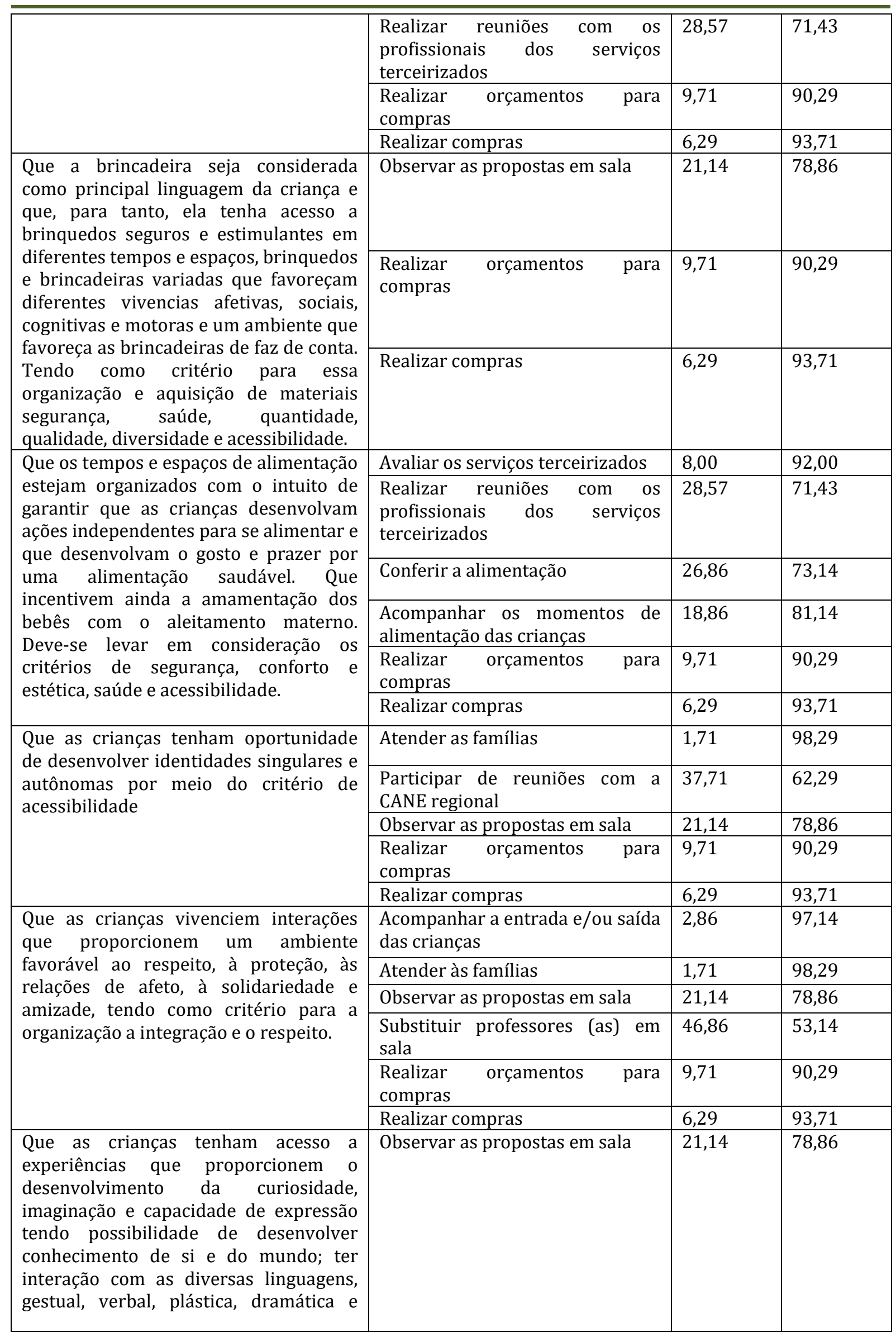


CRUZETTA, D. D. A razão pedagógica das atividades da diretora de Cmei do município de Curitiba e a sua relação com a qualidade do atendimento na educação infantil

\begin{tabular}{|c|c|c|c|}
\hline \multirow{2}{*}{$\begin{array}{l}\text { musical; ter interação com a linguagem } \\
\text { oral e escrita, tendo acesso a diferentes } \\
\text { suportes e gêneros textuais orais e } \\
\text { escritos; ações que recriem relações } \\
\text { quantitativas, medidas, formas e } \\
\text { orientações espaço temporais; } \\
\text { propostas que desenvolvam a } \\
\text { autonomia nas ações de cuidado } \\
\text { pessoal, auto-organização, saúde e bem- } \\
\text { estar; acesso a diferentes manifestações } \\
\text { de música, artes plásticas e gráficas, } \\
\text { cinema, fotografia, dança, teatro, poesia } \\
\text { e literatura; contato e cuidado com a } \\
\text { natureza; construção de conhecimentos } \\
\text { em relação ao mundo físico e social, ao } \\
\text { tempo à natureza; acesso as diferentes } \\
\text { manifestações e tradições culturais } \\
\text { brasileiras; e utilização de recursos } \\
\text { tecnológicos e midiáticos. Tendo como } \\
\text { critério saúde e segurança, uso de } \\
\text { materiais e equipamentos, quantidade, } \\
\text { qualidade, diversidade e acessibilidade. }\end{array}$} & $\begin{array}{l}\text { Realizar orçamentos para } \\
\text { compras }\end{array}$ & 9,71 & 90,29 \\
\hline & Realizar compras & 6,29 & 93,71 \\
\hline \multirow{8}{*}{$\begin{array}{l}\text { Que todos os professores que trabalham } \\
\text { na Educação Básica, inclusive os da } \\
\text { Educação Infantil, em consonância com } \\
\text { a meta } 15 \text { do atual Plano Nacional de } \\
\text { Educação, tenham formação específica } \\
\text { em ensino superior, complementada } \\
\text { com a formação continuada em serviço, } \\
\text { usando como critério para organização a } \\
\text { acessibilidade. }\end{array}$} & $\begin{array}{l}\text { Organizar as faltas de professores } \\
\text { e as permanências }\end{array}$ & 6,86 & 93,14 \\
\hline & $\begin{array}{llll}\text { Participar de reuniões com o } \\
\text { pedagogo (a) para tratar de } \\
\text { assuntos pedagógicos }\end{array}$ & 6,29 & 93,71 \\
\hline & $\begin{array}{lcc}\text { Participar dos } & \text { momentos } & \text { de } \\
\text { permanência } & \text { com } & \text { os } \\
\text { profissionais } & & \end{array}$ & 51,43 & 48,57 \\
\hline & $\begin{array}{l}\text { Participar dos momentos de } \\
\text { supervisão com o Núcleo } \\
\text { Regional de Educação }\end{array}$ & 11,43 & 88,57 \\
\hline & $\begin{array}{l}\text { Participar de formações nos } \\
\text { Núcleos Regionais de Educação }\end{array}$ & 6,29 & 93,71 \\
\hline & $\begin{array}{l}\text { Participar de formações ofertadas } \\
\text { pelo Departamento de Educação } \\
\text { Infantil }\end{array}$ & 20,00 & 80,00 \\
\hline & $\begin{array}{lll}\begin{array}{l}\text { Realizar } \\
\text { compras }\end{array} & \text { orçamentos para } \\
\end{array}$ & 9,71 & 90,29 \\
\hline & Realizar compras & 6,29 & 93,71 \\
\hline \multirow{8}{*}{$\begin{array}{l}\text { Que os Cmeis estejam organizados a fim } \\
\text { de garantir um espaço de convivência } \\
\text { democrática, usando como critério de } \\
\text { organização a transparência, o } \\
\text { planejamento participativo, atenção à } \\
\text { equipe, parceria e avaliação da } \\
\text { instituição. }\end{array}$} & Atender as famílias & 1,71 & 98,29 \\
\hline & $\begin{array}{llll}\begin{array}{l}\text { Participar } \\
\text { conselho }\end{array} & \text { das } & \text { reuniões } & \text { de } \\
\end{array}$ & 4,57 & 95,43 \\
\hline & Elaborar e avaliar o plano de ação & 9,14 & 90,86 \\
\hline & Realizar prestação de contas & 6,86 & 93,14 \\
\hline & $\begin{array}{l}\text { Participar de reuniões com o } \\
\text { pedagogo (a) para tratar de } \\
\text { assuntos pedagógicos }\end{array}$ & 6,29 & 93,71 \\
\hline & $\begin{array}{l}\text { Participar de reuniões com a } \\
\text { Rede de Proteção }\end{array}$ & 32,57 & 67,43 \\
\hline & $\begin{array}{l}\text { Realizar encaminhamentos para a } \\
\text { unidade de saúde }\end{array}$ & 13,71 & 86,29 \\
\hline & $\begin{array}{llr}\text { Realizar } & \text { reuniões } & \text { com } \\
\text { profissionais } & \text { especializados } & \text { que } \\
\text { atendem as crianças } & \end{array}$ & 38,29 & 61,71 \\
\hline
\end{tabular}


CRUZETTA, D. D. A razão pedagógica das atividades da diretora de Cmei do município de Curitiba e a sua relação com a qualidade do atendimento na educação infantil

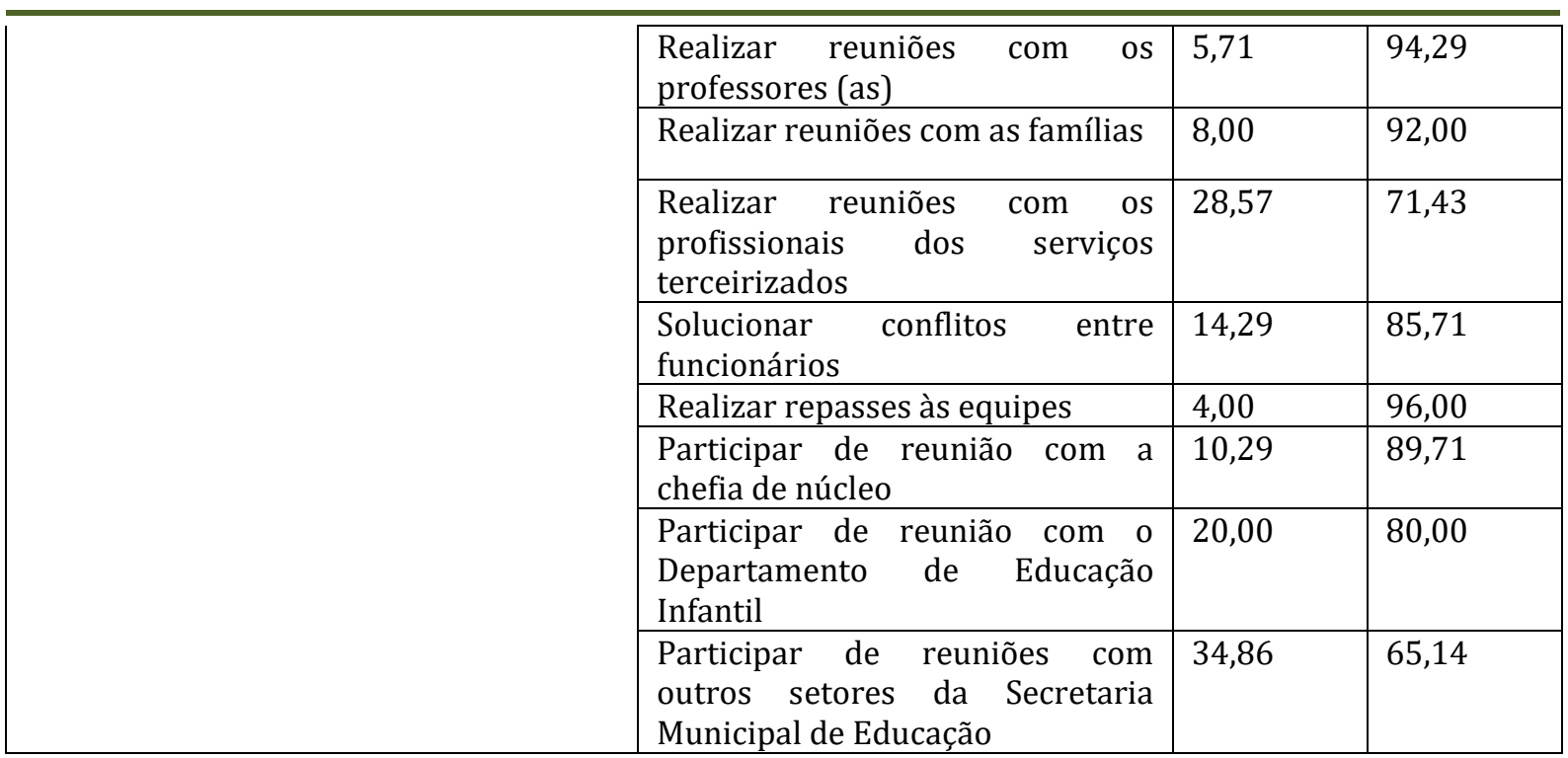

Fonte: Cruzetta (2018).

Com base no quadro acima organizado, percebe-se que algumas atividades aparecem em mais de uma condição de qualidade. A primeira, que aparece em cinco das oito condições de qualidade colocadas no trabalho, é "observar as propostas em sala". Essa foi uma tarefa apontada acima como exemplo de atividade com uma característica inicial mais pedagógica e seu percentual de resposta de frequência foi de $21,14 \%$ das respostas para as menores frequências e 78,86\% das respostas para as maiores frequências. Ela não é uma das atividades que ficam com o nível acima de $80 \%$ das respostas, assim se destaca, sendo essa uma atividade que pode ser realizada com mais frequência pelas diretoras, já que favorece a maioria das condições de qualidade. Sabese que essa pode ser uma tarefa desenvolvida com maior frequência pela pedagoga, porém ela acompanha apenas quatro das 11 horas de jornada oferecida pelo Cmei.

A segunda diz respeito à tarefa de "realizar reuniões com os profissionais dos serviços terceirizados", em que as diretoras declararam as seguintes frequências no questionário: 28,57\% preencheram as menores frequências e 78,86\% as maiores frequências. A referida tarefa está relacionada a três condições de qualidade, dessa maneira, entende-se que esses profissionais estão ligados diretamente à oferta de uma Educação Infantil de qualidade e assim devem participar e entender mais do processo educativo que acontece dentro do Cmei e essa ação pode ser realizada por meio dessas reuniões.

“Atender às famílias" é a terceira tarefa aqui destacada; ela também está relacionada a três condições de qualidade e as diretoras declararam realizá-la com as seguintes frequências: 1,71\% para as menores frequências e 98,29\% para as maiores 
frequências. Com essa resposta percebe-se que a diretora tem consciência da importância dessa tarefa para a qualidade da Educação Infantil.

As outras duas atividades destacadas aqui, com características inicialmente mais administrativas, estão relacionadas à parte financeira, pois as tarefas de "realizar orçamentos" e "realizar compras" aparecem em sete das oito condições de qualidade. As declarações sobre a frequência de realização foram de 9,71\% para as menores frequências e 90,29\% para as maiores frequências para a primeira e 6,29\% para as menores frequências e 93,71\% para as maiores frequências para a segunda. Dessa maneira, percebe-se que as questões financeiras permeiam toda a organização do trabalho, entendendo assim a importância do financiamento e a administração desses recursos para uma educação de qualidade.

Conhecer as condições de qualidade para a oferta da educação infantil e perceber de que forma as atividades do seu cotidiano estão mais diretamente ou menos relacionadas a essas condições pode contribuir para que as diretoras desenvolvam uma consciência da práxis da gestão escolar. Pois, como coloca Paro (1990), por meio dessa consciência, as diretoras podem transitar de uma administração espontânea para uma administração mais reflexiva.

Pode-se perceber ainda no quadro acima que todas as condições de qualidade necessitam da realização de mais de uma tarefa pela diretora, mas destaca-se que a condição de qualidade relacionada à qualificação profissional das professoras que atuam na Educação Infantil necessita de oito tarefas das atribuições da diretora para acontecer, mostrando a importância dessa condição para todo o processo educativo que acontece dentro do Cmei.

A condição de qualidade que trata sobre a gestão democrática é o que tem maior quantidade de atividades que influenciam diretamente para que ela seja alcançada. 0 fato de 16 atividades do cotidiano estarem relacionadas a essa condição de qualidade mostra que a principal função da diretora, sendo de natureza política-pedagógica, é buscar, por meio de suas ações do cotidiano, um espaço de convivência democrática, como aponta o documento PIQ para os Cmeis de Curitiba-PR,

Ações educativas pautadas em relações democráticas são fundamentais para que os diferentes atores envolvidos nesse processo conheçam a realidade social, compartilhem problemas, provoquem reflexões e procurem repensar modalidades de atendimento que respondam aos direitos das crianças e famílias à educação infantil de qualidade (CURITIBA, 2009, p. 69). 
Percebe-se ainda que algumas atividades não foram atribuídas para nenhuma das condições de qualidade estabelecidas para esta pesquisa: a) responder e-mails; b) atender à demanda do NRE e do nível central; c) realizar BF (Boletim de frequência); d) cadastrar LTS (Licença para Tratamento de Saúde) de subordinados; e) organizar malote; f) inserir dados no GED (Sistema de Gestão Educacional); g) acompanhar o trabalho do agente administrativo.

Por não se encaixarem diretamente em nenhuma condição de qualidade, essas atividades podem ser consideradas com características inicialmente mais burocráticas. As ações burocráticas do trabalho da diretora não podem prevalecer sobre a característica política da função, pois essas questões mais burocráticas muitas vezes ocupam o lugar das atividades que trazem consigo uma importante razão pedagógica para existir e ser realizada. Segundo Souza (2007), não se trata de não desenvolver as ações técnicas do trabalho da diretora, mas que essas ações não podem encobrir a face política da função e, especialmente, que nelas estejam contidas ações pedagógicas.

Porém é preciso considerar que essas atividades que não foram relacionadas no momento a nenhuma condição de qualidade podem, em determinadas situações, apresentar uma razão pedagógica, como, por exemplo, nos casos das tarefas relacionas a "responder e-mails" e “organizar malote", pois não é possível saber qual é o conteúdo do e-mail e/ou do malote, ele pode estar relacionado a questões de orientação de organização ou de prestação de contas, que podem impactar na qualidade, o que diferencia é o conteúdo, se essas atividades poderiam ter os fins atingidos por outros meios. Dessa forma, considera-se aqui que essas tarefas estão relacionadas mais indiretamente com as condições de qualidade.

Outras duas atividades ficaram fora do quadro, por não ter uma relação direta com as condições de qualidade estabelecida na pesquisa, sendo:

- Realizar cadastros de matrícula;

- Realizar matrícula.

A questão do acesso não foi discutida neste trabalho, mesmo sendo considerada uma condição para se pensar a qualidade na Educação Infantil. Outras pesquisas podem aprofundar essa questão.

\section{Conclusões}


Percebeu-se na empiria a superação da divisão entre atividades administrativas e atividades pedagógicas, pois é necessário considerar que o pedagógico não se faz no vazio e sim é um conjunto de ações. 0 que a pesquisa revelou foi que existe uma convergência nas ações realizadas pelas diretoras para que se favoreçam as condições de qualidade da Educação Infantil. Assim, conclui-se que o que precisa ser levado em consideração nessa discussão é a razão pedagógica das tarefas que são realizadas pelas diretoras e se essa ação converge para atingir a finalidade da Educação Infantil, ou seja, um atendimento de qualidade. Dessa forma, o que se percebe no cotidiano de trabalho das diretoras de Cmei é a realização de algumas tarefas com características iniciais que são mais burocráticas, como a organização de malote ou o atendimento a demandas do NRE e do nível central. Porém ressalta-se que é necessário levar em consideração o conteúdo dessas atividades para identificar uma relação maior ou menor com as condições de qualidade.

É possível reconhecer a razão pedagógica de cada tarefa desenvolvida pela diretora de Cmei elencada neste trabalho, ao ser relacionada com as condições de qualidade para a Educação Infantil traçadas para essa pesquisa, pois se as tarefas realizadas pelas diretoras favorecem uma ou mais das condições, mostram uma razão pedagógica para existirem e serem realizadas. Para as atividades que não apresentaram inicialmente uma relação com as condições de qualidade, é necessário primeiro entender qual é o seu conteúdo para depois conhecer seu nível de influência nas referidas condições.

\section{Referências}

BRASIL. Ministério da Educação. Secretaria de Educação Básica. Diretrizes curriculares nacionais para a educação infantil. Secretaria de Educação Básica. Brasília: MEC, SEB, 2010.

BRASIL. 2015. Contribuições para a Política Nacional: a avaliação em educação infantil a partir da avaliação de contexto. Curitiba: Imprensa/UFPR; Brasília: Ministério da Educação. Secretaria de Educação Básica. Coordenação Geral de Educação Infantil - MEC/SEB/COEDI, 2015, 104p.

CAMPOS, M. M; FULLGRAF, Jodete; W. V. A qualidade da educação infantil brasileira: alguns resultados de pesquisa. Cad. Pesqui., São Paulo , v. 36, n. 127, p. 87-128, abr/2006.

Disponível

em <http://www.scielo.br/scielo.php?script=sci_arttext\&pid=S01005742006000100005\&l ng=pt\&nrm=iso>. acessos em 03/08/ 2017. 
CAMPOS, Maria Malta et al . A qualidade da educação infantil: um estudo em seis capitais Brasileiras. Cad. Pesqui., São Paulo , v. 41, n. 142, p. 20-54, abr/2011. Disponível em http://www.scielo.br/scielo.php?script=sci_arttext\&pid=S0100-

15742011000100003\&lng=pt\&nrm=iso>. Acesso em 03/08/ 2017.

CAMPOS, M. M. Entre as políticas de qualidade e a qualidade das práticas. Cad. Pesqui., São Paulo , v. 43, n. 148, p. 22-43, abr/2013 . Disponível em <http://www.scielo.br/scielo.php?script=sci_arttext\&pid=S0100-

$15742013000100003 \& \operatorname{lng}=$ pt\&nrm=iso $>$. Acesso em 03/08/2017.

CARVALHO, A. M.; PEREIRA, A. S. Qualidade em ambientes de um programa de educação infantil públicaQuality of environments of a public child education program. Psic.: Teor. e Pesq., Brasília, v. 24, n. 3, p.269-277, set/2008. Disponível em <http://www.scielo.br/scielo.php?script=sci_arttext\&pid=S01027722008000300002\&l ng=pt\&nrm=iso $>$. Acesso em 03/08/2017.

CRUZETTA, D. A. A Influência do Trabalho da Diretora de Cmei na Qualidade do Atendimento na Educação Infantil na Rede Municipal de Curitiba - PR. 225 f. Dissertação (Mestrado em Educação) Programa de Pós-Graduação em Educação. Área de Concentração: Políticas Educacionais. Setor de Educação. Universidade Federal do Paraná. Curitiba, 2018.

CURITIBA. Prefeitura Municipal. Secretaria Municipal de Educação. Parâmetros e Indicadores de Qualidade para os Centros Municipais de Educação Infantil. 2009.

DOURADO, L. F.; OLIVEIRA, J. F. A qualidade da educação: perspectivas e desafios. Cadernos Cedes, Campinas, v. 29, n. 78, p. 201 - 215, maio/ago. 2009.

MELHUISH, E. Efeitos de longo prazo da educação infantil: evidências e política.Cad. Pesqui., São Paulo , v. 43, n. 148, p. 124-149, abr. 2013 . Disponível em <http://www.scielo.br/scielo.php?script=sci_arttext\&pid=S0100-

$15742013000100007 \& \operatorname{lng}=p t \& n r m=i s o>$. Acesso em 03/08/ 2017.

MOSS, P. Para além do problema com qualidade. in: MACHADO, M. L. de A. Encontros e desencontros em educação infantil. - 4. ed - São Paulo: Cortez, 2011, p. 17-25.

PARO, V. H. Administração Escolar: uma introdução crítica. 4 ed. São Paulo: Cortez: Autores Associados, 1990.

SILVA, M. A. Qualidade social da educação pública: algumas aproximações. Cadernos Cedes, Campinas vol. 29, n. 78, p. 216-226, maio/ago. 2009.

SOUZA, A. R. de. Perfil da Gestão Escolar no Brasil. 2007. 302 p. Tese (Doutorado em Educação) - Programa de Pós-Graduação em Educação, Pontifícia Universidade Católica de São Paulo. São Paulo. 2007. 


\title{
JORNAL DE POLÍTICAS EDUCACIONAIS \\ ISSN 1981-1969
}

Volume 12

\section{(C)}

SORERIGHIS RESERNED O Copyright é retido pelo/a autor/a (ou primeiro co-autor) que outorga o direito da primeira publicação ao Jornal de Políticas Educacionais. Mais informação da licença de CreativeCommons encontram-se em http://creativecommons.org/licenses/by-nc-nd/2.5. Qualquer outro uso deve ser aprovado em conjunto pelo/s autor/es e pelo periódico.

JoRnal DE Políticas EduCACiONAis é uma publicação do Núcleo de PolíticasEducacionaisdo Setor de Educação da Universidade Federal do Paraná - NuPE/UFPR, em consórcio com a Linha de Pesquisa em Políticas Educacionais do Programa de Pós-Graduação em Educação - PPGE/UFPR, que aceita colaboração, reservando-se o direito de publicar ou não o material espontaneamente enviado à redação. As colaborações devem ser enviadas ao NuPE/UFPR, conforme orientações contidas nas páginas do periódico na internet: http://revistas.ufpr.br/jpe.

\author{
Indexação: \\ BBE - Biblioteca Brasileira de Educação (MEC/INEP) \\ Clase (Base de Datos Bibliográfica de Revistas de Ciencias Sociales y Humanidades) \\ Diadorim - Diretório de Política de Acesso Aberto das Revistas Científicas Brasileiras (IBICT) \\ Google Scholar \\ Index Copernicus \\ Portal de Periódicos (CAPES) \\ SER - Sistema Eletrônico de Revistas da Universidade Federal do Paraná (SER/UFPR) \\ Sumários de Revistas Brasileiras (FUNPEC-RP) \\ DRJI - Directory of Research Journals Indexing
}

(Periódico integralmente disponível apenas em via eletrônica)

Jornal de Políticas Educacionais / Núcleo de Políticas Educacionais da Universidade Federal do Paraná NuPE/UFPR - v.1, n. 1 (1ํㅗ semestre de 2007) - Curitiba: NuPE/UFPR.

Volume 12, número 22 - Novembro de 2018

ISSN 1981-1969

1. Educação - Periódicos. 2. Política Educacional - Periódicos. I. NuPE/UFPR

Comitê Editorial:

Elisângela Scaff (UFPR)

Ana Lorena Bruel (UFPR)

Gabriela Schneider (UFPR)

Conselho Editorial: 
CRUZETTAA, D. D. A razão pedagógica das atividades da diretora de Cmei do município de Curitiba e a sua relação com a qualidade do atendimento na educação infantil

Andréa Barbosa Gouveia (UFPR), Ângela Hidalgo (UNICENTRO), Cesar GernominoTello (Universidad Nacional TresFebrero, Argentina),Gladys Beatriz Barreyro (USP), Juca Gil (UFRGS), Jefferson Mainardes (UEPG), João Ferreira de Oliveira (UFG), Luiz Souza Júnior (UFPB), Marcos Edgard Bassi (UFSC), Regina Maria Michelotto (UFPR), Robert Verhine (UFBA), Rosana Cruz (UFPI), Rubens Barbosa Camargo (USP), Sebastián Donoso Díaz (Universidad de Talca, Chile), Taís Moura Tavares (UFPR), TheresaAdrião (UNICAMP), Vera Peroni (UFRGS).

\author{
Jornal de Políticas Educacionais \\ Universidade Federal do Paraná \\ Setor de Educação \\ Núcleo de Políticas Educacionais - NuPE/UFPR \\ Rua Gal. Carneiro, 460 - 4o andar - Sala 407/C \\ 80.060-150 - Curitiba - PR - Brasil \\ Tel.: 41-3360-5380 \\ jpe@ufpr.br \\ http://revistas.ufpr.br/jpe
}

